\title{
Theravada Buddhism and Thai Luxury Fashion Consumption
}

\author{
Michael McAleer ${ }^{1,2,3,4, *}$ and Ning Mao ${ }^{5}$ \\ ${ }^{1}$ Department of Quantitative Finance, National Tsing Hua University, Taiwan \\ ${ }^{2}$ Econometric Institute, Erasmus School of Economics, Erasmus University Rotterdam, The Netherlands \\ ${ }^{3}$ Department of Quantitative Economics, Complutense University of Madrid, Spain \\ ${ }^{4}$ Institute of Advanced Sciences, Yokohama National University, Japan \\ ${ }^{5}$ China-Asean International College, Dhurakij Pundit University, Bangkok, Thailand
}

\begin{abstract}
This paper reviews the Thai national character according to Hofstede's $(1991,2001,2017)$ cultural dimension theory and Komin's (1991) nine values cluster (Psychology of the Thai people), analyses the social hierarchy of Thai consumers according to the Luxury 4P Taxonomy (Han et al., 2010), integrates the Theory of Cultural Capital (Bourdieu, $1984,1986)$, and expounds the features of social class. The global luxury fashion industry has grown significantly in recent years, but much of the research has been limited to conspicuous consumption and social identity. This paper involves religious beliefs that are argued to influence luxury purchasing motives. The purpose of the paper is to develop an analytical framework to aid in understanding luxury fashion consumption in a Buddhist country such as Thailand in order to inform luxury products vendors on how to improve their marketing strategies.
\end{abstract}

Keywords: Luxury fashion consumption, Purchasing motives, Buddhist beliefs, Marketing strategies, Thailand. JEL: N35, Z12, Z13.

\section{INTRODUCTION}

Substantial research has indicated that culture can influence consumer behavior broadly and deeply (see, for example, Kotler, 1994). Religion is a subset of culture, and virtually all religious systems serve to influence culture (Cornwell et al., 2005, p. 533). Attitude, subjective norms and behavioral control (such as the theory of planned behavior, Icek Ajzen, 1991, 2002, 2007) are functions of beliefs. Consumers who hold different beliefs may differ in the processes they follow in seeking information and making purchasing decisions (Gao, 2009).

Apart from being the only country in South-East Asia to have never been colonized, Thailand is the largest Buddhist country in the world. Therefore, Thailand has managed to retain over time the wellknown traditions, culture and social attributes that exists today. Over $93 \%$ of Thai citizens believe in Theravada Buddhism, and the religion continues to influence deeply Thai thinking, behavior, and way of life.

Nowadays, the recovering and improving economy has allowed luxury products to become more accessible than in the past, so that a greater number of Thai middle class and pop-conscious youth have

*Address of correspondence to this author at the Department of Quantitative Finance, National Tsing Hua University, Taiwan; Tel: 886-3-571-5131;

E-mail: michael.mcaleer@gmail.com entered this consumption field. Luxury goods in Thailand have continued to record strong growth due to the economic recovery in 2015 (Market Research, 2015). Many new brands have started to emerge in Thailand, such as Dior, Gucci, Louis Vuitton, MCM, and Alexander Wang, among many others. Luxury consumption in Thailand appeals to both local consumers and foreign tourists, but this paper focuses on the domestic market.

In general, luxury can be divided two categories, namely luxury services and luxury products. Restaurants, cruises and hotels are deemed to be luxury services, whereas jewellery, sports cars, cosmetics, designer clothes, and brand-named goods, such as handbags, are to be luxury products. Both types of goods and services belong to the luxurious lifestyle, but luxury services are typically recognized as high-end invisible luxuries, while luxury products are recognized as low-end visible luxuries.

The literature shows that luxury goods provide both private value and social codes for consumers simultaneously. Therefore, research about consumer purchasing behavior toward luxury fashion goods should be conducted under the assumption that consumers can acquire both internal personal value and external social value from purchasing luxury consumer items. Marketing strategies that have been applied successfully in Western markets will not necessarily be successful in East-Asian and other countries (Gao, 2009). 
Although growing wealth has liberated spending power, and has had a profound effect on attitudes regarding luxury products (Precision Marketing, 2006; Wealth-X, 2016), the purchasing motivation of Thai consumers is still different compared with consumers from traditional luxury markets, such as Japan, Europe, USA, and Middle Eastern countries.

Demand for a luxury product can be expressed as:

$q(i)=f(y, p(i), p(j), u(i))$

where

$f$ (.) represents an unspecified functional form that satisfies the regularity conditions for a demand function;

$q(i)=$ quantity demanded of luxury product $i$;

$y=$ income of the representative consumer;

$p(i)=$ price of luxury product $i$

$p(j)=$ price index of luxury and non-luxury product $j$;

$u(i)=$ random error term for luxury product $i$ for purposes of estimation.

In equation (1), it is assumed that $p$ (i) represents the price of the genuine luxury product $i$ rather than its counterfeit counterpart. It is very difficult to obtain prices of counterfeit commodities, which are latent as there are many grades of counterfeit products, and are technically illegal, so that prices would be artificial. It is assumed in the paper that $p(i)$ refers to actual prices of genuine luxury products and not counterfeit products. It is possible that the prices of counterfeit products might appear in $p(j)$, but they are nevertheless latent and hence not reliable.

Aggregate consumption of a commodity is given as:

$c(i)=\operatorname{SUM}\{(i=1, \ldots m)[p(i) q(i)]\}$

which is the sum of the quantity demanded of all luxury fashion products times their respective prices for $m$ fashion products.

The purpose of the paper is to consider how $q(i)$ and $p(i)$ interact to produce $c(i)$ in equation (2), the consumption of luxury fashion consumption in a Buddhist country, specifically Thailand. The emphasis will be on $q(i)$ as $p(i)$ is difficult to obtain.

The remainder of the paper is organized as follows. Section 2 provides some background material, including the purpose and limitations, Section 3 provides a brief literature review, and Section 4 gives some concluding comments.

\section{BACKGROUND}

\subsection{Purpose and Limitations}

Wong and Ahuvia (1998) indicated many of the products are the same in Asian and Western societies, but consumers in these different societies may not buy the products for the same reasons. Culture influences consumers' perceived values, motivations, and beliefs about products, including luxury goods and services. Therefore, the purpose of the paper is to gain a better understanding of Buddhist beliefs that influence Thai luxury consumers' motives, behavior, objective and psychological changes before and after purchasing luxury products.

Komin (1991) provides a deep understanding about the national character, as well as the cognitive dimension. This system consists of nine clusters, and assists in determining an investigative approach and design of survey questionnaires.

1. Ego Orientation indicates that Thai consumers are characterized by the highest ego value of independence and a high level of self-esteem. Therefore, "ego" may be identified with "saving face", and is very sensitive.

2. Grateful Relationship Orientation indicates that Thai interactions are honest and sincere, and the Thai are interested in sincere and deep reciprocal relationships. Although grateful for dominant values underlying important relationships, there are variations found among different groups, which helps to explain certain observable behavioral patterns.

3. Smooth Interpersonal Relationship Orientation indicates that, unlike some Western cultures whose primary values tend to focus on self-actualization, ambitions and achievements, down-playing such values of self-control and politeness, the Thai, after emphasizing "ego" and "grateful relationships", place a high value on a group of 'other-directed' social interaction values. These characteristics project a picture of smooth, kind, pleasant, no-conflict interpersonal interactions. In fact, the first two values of Thai society are care and consideration. 
4. Flexibility and Adjustment Orientation indicates that the Thai are flexible and situationoriented, regardless of different backgrounds and groups. Sometimes, the Thai flexibility is over principles and ideology. This characteristic is substantially different from Western people. For example, Komin (1991) indicated that, when the Prime Minister finally resigned to pave the way to form a new coalition government to include one of the Opposition parties, those Opposition MPs who had previously declared and sworn in public repeatedly that they would "never" join the government with General Chatchai as Prime Minister, found themselves accepting ministerial posts without any apparent embarrassment.

As another example, Komin (1991) indicated that Thailand has about two dozen political parties. However, their policies and ideological differences can hardly be differentiated. Factions in the Thai political system are not based on ideological or policy differences, but rather on personal conflicts and "ingroup" interests. Flexibility and Adjustment Orientation can be used to explain why law enforcement in Thailand is frequently regarded as being inefficient.

5. Religio-Psychical Orientation indicates that the Thai perceive religion as having some influence in their lives, especially in rural rather than urban areas. Komin (1991) argues that a Buddhist doctrinal religious goal is to escape from the clutches of karma and the cycle of rebirths (Samsara), by separating oneself from the world of illusion, thereby gaining wisdom and insight into the karmically conditioned world, underlying the phenomenal world, and ultimately reaching nirvana. However, the Thai are seemingly overwhelmed by the perceived influence of Buddhism in their lives, with most having little rather than a deep knowledge about the religion. Indeed, most Thai do not make conscious efforts to reach nirvana, and can be argued to not necessarily truly believe in nirvana.

Regarding the Religio-Psychical Orientation, Komin (1991) also indicated that the Thai believe each person is born with unequal results of predestined goodness or badness simultaneously. The Thai will use this concept in situations to explain someone else's success or failure. As a result, the Thai always humbly refuse some good suggestions and advice owing to this reason. On the other hand, this reason also reduces extreme psychological pressures on one's inability to measure up to announced and unannounced achievement goals.

6. Education and Competence Orientation indicates that education has been perceived more as a "means" of climbing up the social ladder to attain greater prestige and higher salaries, rather than an end value in itself. On the basis of this phenomenon, it has been argued that the Thai value and place greater importance on form over content, or style over substance.

7. Interdependence Orientation indicates that collaborative behavior is a dominant behavioral pattern in Thailand. Consequently, Thailand is a rare example of successful assimilation of ethnic groups, such as Muslims and Chinese, saving Thailand from the painful experiences of ethnic conflicts and scandals that are prevalent in other countries and regions.

8. Fun-Pleasure Orientation indicates that, when asked about the quote: "Life is short, so one should enjoy as much as one can", the results of numerous questionnaires show that there is greater disagreement than agreement. With regard to planning for the future, the majority of respondents disagreed with the statement that: "The future is uncertain, so there is no need for planning for one's future". The result put doubts to the statement that the "Thai view life as something to enjoy here and now, with very little thought about the future" (Komin, 1991)

9. Achievement-Task Orientation indicates that the achievement value of being ambitious and hardworking to attain one's goals has been consistently ranked as the least important value (23rd) in relation to the remaining questions, with little variation across groups and over time, with the exception of Thai businessmen, who ranked it 19th, with highest of all Thai groups being the Thai of Chinese descendants, who ranked it $13^{\text {th }}$. This finding substantiated certain attributes of the Chinese character that accounts for their success stories of "rags-to-riches". However, all Thai, without exception, ranked hardworking achievements much lower than social relationship values, which seems to be of paramount importance in Thai society (Komin, 1991). 
Summarizing the value clusters, Thailand's national character may be succinctly stated, as follows: ego and face saving; grateful, sincere and deep reciprocal relationships; 'other-directed' social interaction values; flexibility over principle and ideology; religion has some deep influences, but most Thai do not make a conscious effort to reach nirvana; importance on form over content, or style over substance; collaboration and assimilation; enjoying the present, but also considering the future; and paying greater attention to social relationships than individual achievements.

After analyzing the national character, Hofstede's (1991, 2001, 2017) theory and Triandis' (1988, 1989, 1990, 1995) improvement approach can be used to examine analytically the topic of the present paper. Hofstede's cultural dimension theory is a framework for cross-cultural communication. It describes the effects of a society's culture on the values of its members, and how these values relate to behavior. The theory comprises a Power Distance Index (PDI), Individualism versus Collectivism (IDV), an Uncertainty Avoidance Index (UAI), Masculinity versus Femininity (MAS), Long-term Orientation versus Short-term Orientation (LTO), and Indulgence versus Restraint (IND). In this paper, we have chosen two approaches that are explained below, namely PDI and IDV.

Power distance index (PDI) - Komin (1991) indicated that the Thai, with a high power distance, show great respect for authority, rank, and status, while simultaneously accepting a degree of arbitrariness with regard to authority, hierarchy, special privileges, and power as facts of life that are often personalized.

Individualism versus Collectivism - empirical research has shown that consumers in collectivistic cultures hold perceptions and attitudes toward luxury brands that differ from those of consumers in individualistic societies (Phau and Prendergast, 2000; Wong and Ahuvia, 1998).

Komin (1991) also indicated that individualism refers to a loosely knit social framework in which people emphasize only the care and protection of themselves and their immediate family. Collectivism is characterized by a tight social framework, in which people expect others in the group of which they are a part to provide care and protection to the group members. The Thai are undoubtedly collectivist.

Triandis (1995) further indicated that both individualism and collectivism may be either horizontal or vertical. Gao (2009) stated that, in horizontal social relationships, one's self is believed to be more or less like every other self. Conversely, in vertical social relationships, one is assumed to be fundamentally different from other selves. Individuals who are high on the vertical dimension emphasize hierarchy and accept social inequalities within in groups, whereas individuals who are high on the horizontal dimension stress equality and believe that everyone should have equal rights and status.

Horizontal and vertical social relationships can distinguish various degrees of individualism and collectivism, such as horizontal collectivism ( $\mathrm{HC})$, vertical collectivism (VC), horizontal individualism $(\mathrm{HI})$, and vertical individualism (VI).

According to Singelis et al. (1995), Triandis and Gelfand (1998) and Gao (2009), Vertical Individualists are independent and perceive themselves as different from other selves. They desire to be distinguished from others and to acquire high status, and enjoy and win competition against others. Horizontal Individualists are not interested in being distinguished from others or in having high status, although they are nevertheless independent and want to be unique and highly selfreliant. They seek individuality rather than distinctiveness.

Vertical Collectivists submit to the norms of their ingroups and are willing to sacrifice their personal identities for the benefit of in-group goals for the integrity of the in-group. Horizontal collectivists do not submit easily to authority, although they stress the wellbeing and common goals of their in-group, and are interdependent.

Integrated with the conclusion of the National Character of Thailand, it is clear that the Thai are Vertical Collectivists. Moreover, interpersonal influences are remarkable in ta collectivist society such as Thailand.

In general, luxury consumption is the result of multiple motivations, among which are included the following three interpersonal effects, namely: (i) the Veblen effect, whereby consumers purchase a higherpriced commodity or service when a lower-priced substitute is available; (ii) the Snob effect, whereby demand for a product by a high income segment varies inversely with the demand by a lower income segment); and (iii) the Bandwagon effect, whereby individuals will purchase a commodity or service 
primarily because other individuals are doing so, regardless of their beliefs.

In addition, personal effects, such as Hedonic and Perfectionism, also influences consumer's motives (Vigernon and Johnson, 1999). Luxury products allow and entice consumers into believing that, through consumption, they can contemporaneously gain five values, namely conspicuous, unique, social, hedonic and perceived quality.

Vigernon and Johnson (1999) indicated that: (i) conspicuous value refers to consumption of luxury goods that are viewed as a signal of status and wealth; (ii) unique value refers to the purchase of luxury goods for the purpose of expressing a need for uniqueness to enhance self-image and social image; (iii) social value explains that consumers use luxury products to conform to prestige groups, or to be distinguished from non-prestige reference groups; (iv) hedonic value is emphasized by consumers who desire subjective intangible benefits, such as sensory gratification; and (v) perceived quality value occurs when consumers value the perceived utility acquired from luxury products to suggest superior quality and service.

These effects have been verified in the western cultural environment, but have not yet been examined under Buddhism.

Luxury goods provide a code to assist consumers to communicate personal status, and hence gain recognition, approval, or acceptance from their reference groups (O'Cass and McEwen, 2004). As a result, the social effects can also determine consumers' motives.

According to Bourdieu (1984, 1986), social life can be perceived as a multidimensional status game in which people compete through three types of capital, namely Economic, Social and Cultural. Economic Capital refers to financial resources; Social Capital describes an individual's organizational affiliations and networks; and Cultural Capital refers to a set of socially rare and distinctive tastes, skills, knowledge, and practice (Holt, 1998).

For example, the social class factor always impacts on luxury fashion consumption because upper-class and higher-income consumers hope that, through the purchase of luxury goods, they will expand and consolidate their class advantage, while the middle class may use the purchase of luxury goods to reduce the gap with the upper class (O'Cass and McEwen, 2004)

In order to distinguish social classes for a more detailed analysis, a taxonomy that is called Luxury $4 \mathrm{P}$ is chosen. This taxonomy was proposed by Han, Nunes and Dreze (2010), and is used to define customer segmentation in the purchase of luxury products. The model is based on how consumers can be classified with respect to luxury purchases. After breaking down different demographics and motivations, we can obtain 4 consumer bases, namely Patricians, Parvenus, Poseurs, and Proletarians:

(1) Patricians are equivalent to birth-rich, have high wealth, and do not lust after status. Their status manifestation is much more discrete, which makes it more complex to target for marketers.

(2) Parvenus are usually called the new-rich, so they also have high wealth, but are different from Patricians. Parvenus definitely lust after status, such as exotic sports cars and Hermes bags to reduce the gap with Patricians, while simultaneously disassociating themselves from consumers who cannot attain such luxuries.

(3) Poseurs desire smooth life purchases, though most of the time they do not have sufficient funds to achieve their consumption goals. They seem to mimic Patricians or Parvenus, but they do not lust after status.

(4) Proletarians are not affluent or status conscious, so they do not have any motivation for luxury consumption.

Consequently, Patricians, Parvenus and Poseurs all are feasible luxury consumers, but their purchasing motives are totally different.

Patricians are likely to purchase genuine luxury fashion products, and are unlikely to purchase counterfeit products. Like Patricians, Parvenus are also likely to purchase genuine luxury fashion products, but may, to some extent, also purchase counterfeit products. Poseurs are the most likely to purchase counterfeit rather than genuine luxury products, while Proletarians are not likely to purchase any type of luxury fashion products, whether genuine or counterfeit.

Wan (2012) states that, if a person has low cultural capital but high economic capital, they tend to define 
social status by wealth. Therefore, they will be high in consumption-related needs for status and would be in favor of conspicuous consumption and show appropriate signals, like Parvenus.

If a consumer simultaneously has high cultural capital and economic capital, then such a consumer will tend to define their social status through cultural rather than economic capital, like Patricians. In general, consumers are inclined to define their status using favorable capital (Lenski, 1954; Nam, 2008; Schaninger, 1981).

Holt (1998) divides respondents into High Cultural Capital and Low Cultural Capital. The evaluation method is based on three primary sources, namely family upbringing, formal education, and occupational culture. The indicator follows the suggestion in Holt (1998) and Üstüner and Holt (2010), and is calculated as follows:

Cultural Capital $=[($ Father's Education + Father's Occupation + Mother's Education + Mother's Occupation) / 4] + Education + Occupation

Based on economic, social and cultural factors, Thai luxury consumers may be divided into seven groups, among which five groups could be classified as potential luxury consumers:

(1) Patricians: High Cultural Capital / High Economic Capital;

(2) Parvenus: High Cultural Capital / High Economic Capital;

(3) Parvenus: Low Cultural Capital / High Economic Capital;

(4) Poseur: High Cultural Capital /Low Economic Capital;

(5) Poseur: Low Cultural Capital /Low Economic Capital.

Religion is widely regarded as a subset of culture, and all religious systems serve to influence culture (Cornwell et al., 2005). Jamal (2003) indicated that religious commitments and beliefs influence consumers' feelings and attitudes toward consumption, including luxury consumption, so this effect needs to be investigated.

Over $93 \%$ of Thailand's population is Theravada Buddhist. Therefore, religious beliefs run deep and permeate nearly every aspect of life and affect every social level. Buddha's sermons consists of the Four Noble Truths, and are fundamental principles of nature (Dhamma), which emerged from the Buddha's radically honest and penetrating assessment of the human condition.

The Four Noble Truths are not only metaphysical theories and articles of faith, but are also categories by which it is possible to frame a consumer's direct experience in a way that is conducive to Awakening (Theravada Buddhism: A Chronology, 2017). The Four Noble Truths are comprised of four doctrines, namely Dukkha, Samudaya, Nirodha and Magga, which may be explained in a simple manner, as given below:

(1) Dukkha means suffering, craving, and discontent.

(2) Samudaya explains the cause of craving, suffering and dissatisfaction.

(3) Nirodha describes how to stop this craving and clinging, so that nirvana is attained, and rebirth and dissatisfaction will no longer arise.

(4) Magga is the path to the cessation, or liberation from dukkha. Following the path, restraining oneself, cultivating discipline, and practicing mindfulness and meditation, means that craving and clinging will end, as will rebirth and dissatisfaction.

Theravada Buddhist's doctrines are complicated, with the Four Noble Truths comprising a very small part of the whole system. At the same time, Four Noble Truths are also fundamental of the doctrinal system, so it has a huge influence on true believers.

The four Noble Truths emphasize restraining lust and greed, so that liberation from dukkha, and subsequently rebirth and dissatisfaction, are achieved. On the other hand, research has suggested that lusting after status and social signals are the primary purchasing motives for luxury consumers. Therefore, it is essential to make clear and explain existing influences between Buddhist beliefs and the purchasing of luxury consumption.

\section{BRIEF LITERATURE REVIEW}

Ajzen (1991) developed the theory of planned behavior (TPB), which is essentially an extension of the theory of reasoned action. A fundamental assumption 
of TRA is that most human behavior is deemed to be under volitional control, and so can be predicted from intention alone. TPB was developed to deal with situations in which people may lack complete volitional control over the behavior in question (Ajzen, 2002).

Ajzen (1991) extended the attitude toward behavior and subjective norm constructs to include perceived behavioral control in the model to deal with on-volitional situations. The extension makes it possible to explain behaviors that individuals intend to do, but are hampered due to a lack of confidence or control (Miller, 2005).

Bourdieu (1984, 1986) examines status consumption by introducing a new construct called Cultural Capital. He argues that "the generative mechanism for a model of social organization is competition for various types of capital within social fields" (Holt, 1998). According to Bourdieu (1984, 1986), social life can be perceived as a multidimensional status game in which people compete based on three types of capital, namely Economic, Social and Cultural Capital.

As explained above, Economic capital refers to financial resources; Social capital describes an individual's organizational affiliations and networks; and Cultural capital refers to a set of socially rare and distinctive tastes, skills, knowledge, and practice. In general, individuals are inclined to define their status using their favorable capital (Lenski, 1954; Nam, 2008; Schaninger, 1981).

Hofstede (2017) noted that Thailand, with a score of 20 , is a highly collectivist country. A collectivist consumer may purchase luxury goods to gain external social status (Gao, 2009). According to the definitions and descriptions given above, a deductive conclusion regarding Thai consumers might be as follows:

(1) Patricians will use luxury goods to extend the status gap with other groups;

(2) Parvenus may use the same approach to reduce the gap with Patricians;

(3) Patricians will extend the gap with Poseurs and Proletarians;

(4) Poseurs exhibit greater interest in luxury goods in order to compensate for their lack of status.

On the other hand, consumers are inclined to use their favorable Economic, Social or Cultural Capital to show themselves (Lenski, 1954; Nam, 2008; Schaninger, 1981). For example, Patricians possess high cultural, social and economic capital, but they tend to mark their status by their cultural capital and are less likely to display their economic capital. Parvenus are high in economic capital but low in cultural capital, so they will tend to mark their social status on the basis of the former.

As discussed previously, religion is a subset of culture and virtually all religious systems serve to influence culture (Cornwell et al., 2005, p. 533). In general, religious beliefs play a significant part in sculpting social behavior. Differences in religious affiliations tend to influence the way individuals live, the choices they make, what they eat, and with whom they associate, among other decisions.

For example, taboo foods and drinks are established in religious texts that forbid the consumption of pork or alcohol. Some Islamic countries have ruled that both men and women must cover their torso and upper legs at all times. In the case of women, some religions dictate that only their faces may be exposed in public (Deng et al., 1994).

Many religious teachings suggest that money and materialism are the root of all evil. On the other hand, a study on the Korean-Canadian community found that religious people from developing countries tend to be materialistic, relying on material goods to increase their social status. This finding can be used to argue that attitudes towards luxury brands serve an important social function in establishing and maintaining a social identity (Cleveland and Chang, 2009).

The two major schools of Buddhism, Theravada and Mahayana (2017), are to be understood as different expressions of the same teachings of the historical Buddha. As a matter of fact, both agree upon and practice the core teachings of the Buddha's Dharma, despite a schism after the first council after the death of the Buddha. The earliest available teachings of the Buddha are to be found in the Pali literature, and belong to the school of the Theravada, which may well be called the most orthodox school of Buddhism.

This school admits the human characteristics of the Buddha, and is characterized by a psychological understanding of human nature, and emphasizes a meditative approach to the transformation of consciousness. Sri Lanka, Cambodia, Laos, Burma, and Thailand have accepted the principles of the 
Theravada school, and any differences that might exist between the various schools is essentially restricted to minor matters (Buddhanet.net, Theravada and Mahayana, 2017).

Theravada Buddhism emphasizes Four Noble Truths and equality of all sentient beings. Over $95 \%$ of the Thai people are Theravada Buddhism believers, so Theravada Buddhism has the same influence on all social classes. Research has suggested a divergence of intentions between different social classes, such as Patricians and Parvenus (Wan, 2012).

This paper has outlined a method for testing and demonstrating the doctrine's underlying influences for Thai luxury consumers' attitudinal behavior, subjective norms, and perceived behavior, in order to explain the underlying relationship between religious beliefs and purchasing motives of luxury goods and services.

Buddhism is the philosophy of the awakening and refraining from greed (buddhanet.net, Theravada and Mahayana (2017)). Originating as a monastic movement within the dominant Brahman tradition of the day, Buddhism quickly developed into a distinctive religion. Buddhists believe in karma and reincarnation, engaging in good deeds, using polite words, and experiencing gentle thoughts. Language must be respectful, and expressions of sexuality and anger should be limited.

Buddhism does not encourage materialism, and Buddhists are not inclined to self-indulge, be materialistic or exploit others. Buddhists believe in peace, and their ultimate goal in life is to reach nirvana, which is variously described as paradise, enlightenment, and a state of tranquility (Encarta, 1997).

According to Dillon (1998), Buddhism's goal is to eliminate desires through personal discipline. Buddhists also believe in good conduct, honesty, and being compassionate, charitable and selfless. Morgan and Lawton (1996) claim that the whole ethos for living as a Buddhist is simplicity, self-control, kindness, and generosity. Buddhism also emphasizes that everything is impermanent, so that everything is without permanent soul or self, which is characterized by suffering and the fact that no happiness lasts forever.

The Buddhist doctrine emphasizes equality of all sentient beings and anti-materialism. Therefore, Patricians maybe dislike the use luxury goods to extend their status gap with the other groups. Parvenus may have a similar attitude. Even Patricians may want something that Proletarians use, and thereby to reduce the gap between them.

In summary, it can be argued that a status gap does not actually exist in Thai society as everyone is a follower of Buddha, so that each individual has already obtained an equality in the religious and/or ephemeral world. In this sense, Thai Parvenus and Poseurs are likely to have a lower desire for luxury consumer goods and services.

\section{CONCLUSION}

This paper reviewed the Thai national character, analysed the social hierarchy of Thai consumers, integrated the theory of cultural capital, and expounded on the features of social class, in respect of Theravada Buddhism and Thai luxury fashion consumption.

The global luxury fashion industry has grown significantly in recent years, but much of the research has been limited to conspicuous consumption and social identity. The paper involved religious beliefs that were argued to influence luxury purchasing motives. The paper developed an analytical framework to assist in understanding luxury fashion consumption in a Buddhist country such as Thailand in order to inform luxury product vendors on how to improve their marketing strategies.

The beliefs of Buddhism do not seem to have a significant impact on Thai luxury fashion consumption. Both interpersonal and personal effects play an important role in Thailand, so that other reasons and factors for luxury fashion product purchasing decisions are crucial. A detailed quantitative analysis using actual quantity demand, income and prices of luxury fashion products will enable a deeper examination of this complicated but challenging topic.

\section{ACKNOWLEDGEMENTS}

The authors wish to thank two reviewers for very helpful comments and suggestions. For financial support, the first author acknowledges the Australian Research Council and the National Science Council, Ministry of Science and Technology (MOST), Taiwan.

\section{REFERENCES}

Ajzen, I. (1991), The theory of planned behavior, Organizational Behavior and Human Decision Processes, 50(2), 179-211. https://doi.org/10.1016/0749-5978(91)90020-T 
Ajzen, I. (2002), Perceived behavioral control, self-efficacy, locus of control, and the theory of planned behavior, Journal of Applied Social Psychology, 32(4), 665-683. https://doi.org/10.1111//.1559-1816.2002.tb00236.x

Ajzen, I. (2007), Theory of Planned Behavior., retrieved 5 May 2007, from: http://www.people.umass.edu/aizen/index.html/

Bourdieu, P. (1984), Distinction, Cambridge, MA: Harvard University Press.

Bourdieu, P. (1986), The Forms of Capital, in J. Richardson (ed.), Handbook of Theory and Research for the Sociology of Education, Greenwood, New York, pp. 241-258

Cleveland, M., Chang, W. (2009), Migration and materialism: The roles of ethnic identity, religiosity and generation, Journal of Business Research, 62(10), 963-971. https://doi.org/10.1016/j.jbusres.2008.05.022

Cornwell, B., Cui, C.C., Mitchell, V., Schlegelmilch, B., Dzulkiflee, A., Chan, J. (2005), A cross-cultural study of the role of religion in consumers' ethical positions, International Marketing Review, 22(5), 531-546. https://doi.org/10.1108/02651330510624372

Deng, S., Jivan, S., Hassan, M.L. (1994), Advertising in Malaysia: A cultural perspective, International Journal of Advertising, 13(2), 153-66.

Dillon, E. (1998), China: A Historical and Cultural Dictionary, Curzon Press, Surrey.

Encarta (1997), Encarta, Encyclopedia 1993-1998, Microsoft Corporation.

Gao, L. (2009), Understanding consumer purchasing behavior regarding luxury fashion related goods in China, Hong Kong Polytechnic University Institute of Textiles and Clothing.

Han, Y.J., Nunes, J.C., Dreze, X. (2010), Signaling status with luxury goods: The role of brand prominence, Journal of Marketing, 74, 15-30. https://doi.org/10.1509/jmkg.74.4.15

Hofstede, G. (1991), Cultures and Organizations: Software of the Mind, London McGraw-Hill.

Hofstede, G. (2001), Culture's Consequences: Comparing Values, Behaviors, Institutions, and Organizations across Nations (2nd Ed.), Thousand Oaks, CA: Sage Publications.

Hofstede, G. (2017), Thailand, available at: https://geerthofstede.com/thailand.html, accessed 3 February 2017.

Holt, D.B. (1998), Does cultural capital structure American consumption?, Journal of Consumer Research, 25(1), 1-25. https://doi.org/10.1086/209523

Jamal, A. (2003), Marketing in a multicultural world: the interplay of marketing, ethnicity and consumption, European Journal of Marketing, 37(11/12), 1599-1620. https://doi.org/10.1108/03090560310495375

Komin, Suntaree (1991), Psychology of the Thai People: Values and Behavioral Patterns, Research Center, National Institute of Development Administration.

Kotler, P. (1994), Marketing Management: Analysis, Planning, Implementation, and Control (8th Ed.), Englewood Cliffs, NJ: Prentice-Hall.

Kumar, A., Lee, H.J., Kim, Y.K. (2009), Indian consumers' purchase intention toward a United States versus local brand, Journal of Business Research, 62(5), 521-527. https://doi.org/10.1016/j.jbusres.2008.06.018

Lenski, G.E. (1954), Status crystallization: A non-vertical dimension of social status, American Sociological Review, 19(4), 405413. https://doi.org/10.2307/2087459

Market Research, Luxury Goods in Thailand (2015), available at: http://www.marketresearch.com/Euromonitor-Internationalv746/Luxury-Goods-Thailand-9716245/
Miller, K. (2005), Communications Theories: Perspectives, Processes, and Contexts, New York: McGraw-Hill.

Morgan, P., Lawton, C. (1996), Ethical Issues in Six Religious Traditions, Edinburgh University Press, Edinburgh.

Nam, E. (2008), Status inconsistency and lifestyle among status groups: Focusing on cultural capital and social capital, Development and Society, 37(2), 169-186.

O'Cass, A., McEwen, H. (2004), Exploring consumer status and conspicuous consumption, Journal of Consumer Behavior, 4(1), 25-39. https://doi.org/10.1002/cb.155

Phau, I., Prendergast, G. (2000), Consuming luxury brands: The relevance of the 'Rarity Principle', Journal of Brand Management, 8(2), 122-138. https://doi.org/10.1057/palgrave.bm.2540013

Precision Marketing (2009), Consumer Insight: Luxury as Much to do with Emotions as Possessions, London, pp. 13, available at: http://goliath.ecnext.com/coms2/gi_0199-

6061948/CONSUMER-INSIGHT-Luxury-as-much.html (accessed 18 October 2009).

Schaninger, C.M. (1981), Social class versus income revisited: An empirical investigation, Journal of Marketing Research, 18(2), 192-208.

https://doi.org/10.2307/3150954

Singelis, T.M., Triandis, H.C, Bhawuk, D.P.S., Gelfand, M.J. (1995), Horizontal and vertical dimensions of individualism and collectivism: A theoretical and measurement refinement, Cross-Cultural Research, 29(3), 240-275. https://doi.org/10.1177/106939719502900302

Theravada, the Teachings of the Elders, accessed at: http://www.buddhanet.net/e-learning/buddhistworld/schools1. $\mathrm{htm}$

Theravada Buddhism: A Chronology (2017), accessed 3 February 2017 at http://http://www.accesstoinsight.org/history.html

Theravada and Mahayana, The Buddhist Schools, available at: http://www.buddhanet.net/e-learning/buddhistworld/ schools1.htm (accessed 3 February 2017).

Triandis, H.C. (1988), Cross-cultural contributions to theory in social psychology, in M.H. Bond (Ed.), The Cross-cultural Challenge to Social Psychology, Newbury Park, CA: Sage Publications.

Triandis, H.C. (1989), The self and social behavior in differing cultural contexts, Psychological Review, 96(3), 506-520. https://doi.org/10.1037/0033-295X.96.3.506

Triandis, H.C. (1990), Theoretical concepts that are applicable to the analysis of ethnocentrism, in R.W. Brislin (Ed.), Applied Cross-cultural Psychology, Newbury Park: Sage Publications. https://doi.org/10.4135/9781483325392.n2

Triandis, H.C. (1995), Individualism and Collectivism, Boulder, Colorado, Westview Press.

Triandis, H.C., Gelfand, M.J. (1998), Converging measurement of horizontal and vertical individualism and collectivism, Journal of Personality and Social Psychology, 74(1), 118-128. https://doi.org/10.1037/0022-3514.74.1.118

Üstüner, T., Holt, D.B. (2010), Toward a theory of status consumption in less industrialized countries, Journal of Consumer Research, 37(June), 37-56. https://doi.org/10.1086/649759

Veblen, T.B. (1899), The Theory of the Leisure Class, Boston: Houghton Mifflin.

Vigneron, F., Johnson, L.W. (1999), A review and a conceptual framework of prestige-seeking consumer behavior, Academy of Marketing Science Review, 1, 1-15.

Wan,Y. (2012), The impact of status seeking and product type on the purchase of luxury goods and luxury experiential services, 
Pennsylvania State University, Graduate Scholl College of Health and Human Development.

Wealth-X (2016), Four Challenges for Luxury Brands in 2016, available at: http://www.wealthx.com/articles/2016/ challenges-luxury-brands-2016
Wong, N.Y., Ahuvia, A.C. (1998), Personal taste and family face: Luxury consumption in Confucian and Western societies, Psychology \& Marketing, 15 (5), 423-441.

https://doi.org/10.1002/(SICI)1520-

$\underline{6793(199808) 15: 5<423:: A I D-M A R 2>3.0 . C O ; 2-9}$

Received on 29-12-2016

Accepted on 25-01-2017

Published on 22-02-2017

DOI: https://doi.org/10.6000/1929-7092.2017.06.05

(c) 2017 McAleer and Mao; Licensee Lifescience Global.

This is an open access article licensed under the terms of the Creative Commons Attribution Non-Commercial License (http://creativecommons.org/licenses/by-nc/3.0/) which permits unrestricted, non-commercial use, distribution and reproduction in any medium, provided the work is properly cited. 